\title{
10
}

\section{Maps as objects}

\section{Tuur Driesser}

\section{The PathoMap}

In September 2013, New York University (NYU) announced an award of $\$ 250,000$ to two teams of researchers as part of the presidential Grand Challenge competition dedicated to promoting 'significant scientific research that has the potential to solve major national or global problems' (New York University, 2013: no pagination). One of these teams, comprised of researchers from a number of the university's research centres, including the Center for Genomics and Systems Biology and the Center for Urban Science and Progress (CUSP), won its award based on a proposal to analyse New York's metagenome in order to map the city's microbiome. This means that by analysing the genetic material found in environmental samples from subway stations and parks throughout the city and tagging these with GPS coordinates, a map is created indicating the locations of the city's microbial communities. With its capacity for data collection and analytics, CUSP contributes to Weill Cornell Medical College's 'PathoMap' project (Dale, 2013), which was an experiment that used next-generation DNA sequencing methods to eventually monitor pathogens and dangerous organisms in real-time as they emerge within a country or city. By the project's first evaluation (Afshinnekoo et al., 2015), researchers had collected, catalogued and analysed a total of 1,457 environmental samples, providing a base line map of New York City's 'microscopic residents' (PathoMap, n.d.). In future stages, this project could enable first responders and specialised threat teams to act quickly to contain and remove a biological threat: 
specifically, we propose to leverage our previous work in multi-layered microbe detection and human sequencing to establish a 'pathogen weather map,' or 'PathoMap,' whereby the microbiotic population and genetic dynamics in a city can be used to detect and respond to increases in microbial dangers. (PathoMap, n.d.)

Using the new possibilities offered by DNA sequencing technologies developed in the analysis of the human genome, in combination with GIS software, researchers hope to closely approximate a real-time map of New York's microbiological life. Ultimately, the PathoMap is aimed to function as a monitoring device to enable quick detection of pandemic threats - in particular in relation to bioterrorism - and subsequent intervention.

Here, this case of the PathoMap as a monitoring device will serve to explore some questions concerning maps and temporality. In particular, the argument will emphasise not the representation of time through maps, but rather the way in which maps themselves affect, direct and produce time. Promoting the Picturing Place project at the University College London 'Urban Laboratory', Campkin, Mogilevich and Ross (2014: no pagination) write that:

[w] hen we make things visible, we make them public and subject to debate. Urban images not only offer insights to help analyse and understand cities, but also point to ways of radically altering their futures.

However, as will be suggested here, the way in which urban images - maps - can change these futures is not (only) by 'producing evidence for physical change' (Campkin, Mogilevich and Ross, 2014: no pagination) to make things public. Instead, more than an independent, transparent and accessible layer, maps take part in the production of urban space (increasingly so with the proliferation of digital visualisations). Thus, a map will be considered as part of an urban assemblage and, consequently, as a constitutive part of the city's functioning. That is not to say that the map and the city are the same, or exist only in relation to one another, but that their encounter is a specific constellation - sometimes temporary, sometimes more permanent. Within such constellations, through their visualisation mechanisms, maps draw together and drive apart; separate and augment (Hookway, 2014); enable and disable. In the case of the PathoMap, it will be explored how exactly the mapping of the NYC microbiome produces a particular configuration of space and time within this urban assemblage. The main issue thus addressed concerns the way in which the PathoMap establishes relationships between the present and the future of the city. The critical object-oriented question ultimately becomes how maps of the present can enable the opening-up or closing-down of the future and, consequentially, make possible (or impossible) a social imagination that takes seriously the openness of this future. 


\section{From critical to object-oriented cartography}

The critical cartography which arose in the 1990s (Crampton and Krygier, 2006) approach maps as texts (Harley, 1989), sign systems (Wood, 1993) and social constructions (Crampton, 2001). In response to the dominance of the communication model, which thought of maps purely as neutral tools to convey geographical information, critical cartography sought to demonstrate how these representations were in fact bound up with politics of power and knowledge. Thus, building on Foucault and Derrida (Harley, 1989), the project of critical cartography was to deconstruct the map in order to reveal it as a 'specific set of power-knowledge claims' (Crampton and Krygier, 2006: 12). Accordingly, within the field of critical cartography, research shifted from determining the most efficient methods for communication to examining how power finds its expression in maps. Yet despite their critique of representation, Kitchin and Dodge (2007) note that writers, such as Harley and even Crampton, still operate within an essentially representational framework. As such, one of the implications of emphasising 'intertextuality' for Harley (1989) was the possibility of looking beyond the map maker's intentions in order to find other, suppressed and competing, narratives. Here, this analogy of maps and texts by Harley will be revisited by examining maps through the lens of some recent ideas about literary criticism from 'new materialists', such as Bennet (2012), Harman (2012) and Hayles (2014). This will lead into a proposal for an object-oriented cartography in which maps again figure as texts, not with the purpose of deconstruction, but to argue against Wood's (1993: 81) assertion that 'their quality as things is less significant than their quality as signs'.

If the constructivist approach of critical cartography challenged the idea of neutrality of representation as formerly presupposed by the communication model, an object-oriented critical cartography contributes to destabilising the communicational function of a map. It describes how maps operate in all sorts of ways, besides merely conveying geographical information. Harman's (2012) objectoriented philosophy is useful here as it warrants the map against 'undermining' descriptions which explain objects in terms of their constituent elements, such as those attempts under the communication paradigm to improve map design by optimising its various components. At the same time, it warns against 'overmining' the map by explaining it as the obverse of some larger structures - e.g. as an expression of the mapmaker's culture, ideology, consciousness, and so forth. In opposition to constructivist frameworks, an object-oriented critical cartography affirms the map's connection to the territory. As part of the (speculative) realist project, it takes a step back from that all-encompassing prison-house of language 
to return some sense of ontological security to the territory. This is cartography as what Kurgan (2013: 34-36) calls a 'para-empirical' analysis: an 'effort at once to reclaim a sense of reality, and not to imagine that this requires doing away with representations, narratives, and images'. Acknowledging the inherently abstracting qualities of representation, it re-evaluates the relationship of the map to the territory as one that is a representation, but a representation that exists 'alongside the world' rather than on top of it.

Such a framework does not necessarily need to altogether reject discursive analyses in favour of a 'materialist' approach, but rather asserts the latter as a 'useful counter' to the former (Bennett, 2004: 358). The object-oriented approach, and the wider philosophical movement of speculative realism more generally, points towards the limits of deconstructive, language-focused critiques. With respect to maps, the deconstructionist work of the early critical cartographers has been fundamental for questioning the neutrality of maps. As Bryant (2013) describes, poststructuralist-oriented critiques of critical theory have been important in various emancipatory political struggles where it was necessary to demonstrate how categories such as gender and race were culturally constructed. Nevertheless, it is also clear that not all forms of power are necessarily reducible to issues of discourse. Harley (1989) briefly touches upon the 'power external to maps and mapping', referring to the deployment of maps for the exercise of power, mainly in the context of surveillance and control. It may even be granted that his distinction between internal and external power becomes rather blurred at times. The main point, however, is that while critical cartography is crucial to understand how power is expressed in seemingly neutral maps, its fundamentally constructivist focus falls short of addressing how the power of the map is exerted on the world in the first place.

Object-oriented cartography aims to confront this shortcoming of the limits of critical cartography's capability to explain the power of maps. Thus, moving beyond hermeneutic cartographic interrogations, maps can for instance be considered as: devices (Marres, 2012; Law and Ruppert, 2013), apparatuses (Agamben, 2009), objects (Harman, 2012) or things (Bennett, 2004). The function of these conceptualisations is to suggest that maps, possessing some degree of coherence, with more or less distinct boundaries, fulfil particular roles by their 'capacity to capture, orient, determine, intercept, model, control, or secure the gestures, behaviours, opinions, or discourses of living beings' (Agamben, 2009: 14) and, as should be added in this context, non-living objects. Most importantly, what these conceptualisations have in common is the emphasis on the need to take seriously the materiality of objects and their affective capacities. This framework is related to literature in post-representational cartography (Perkins, 2004), itself associated with the non-representational turn in 
geography, and the social sciences more generally. Rather than focusing on what is and what is not represented, it is key to understand 'how mappings emerge, circulate and do work in the world' (Kitchin, Gleeson and Dodge, 2013: 483).

Accordingly, the focus shifts from the issue of representation, and partially sidesteps more general questions of abstraction to ask exactly how maps effect, relate, enact and affect (Darling, 2014: 485). More specifically with respect to the question of temporality, it is a question of how maps are involved in 'generating spatio-temporal atmospheres' (Ash, 2013: 26). This implies not a general linear notion of time, but one specific to the encounter between the map and its territory. Time thus conceived, Bryant (2013: 20) argues, is counted among 'those properties that really do belong to things and the efficacy things organise on other things'. It originates in the encounter between the map and its territory; not simply as the result of their relationship as such, but through the map's particular 'capacity ... to move, threaten, inspire, and animate (Bennett, 2004: 358). Thus, the PathoMap, in its encounter with New York's metagenome, affects urban space such that it enacts a configuration of space and time. The question for an object-oriented cartography is to describe how exactly the map affects the urban and, consequently, what sort of time this involves. In particular, in this case of the PathoMap, it will explore to what extent it allows for a social imagination of the future.

\section{Urban informatics and the logic of preparedness}

The aspiration for the PathoMap to approach ever more closely a real-time representation of the New York City microbiome is envisioned as a project of urban informatics. The latter, as the driver behind smart cities, is founded on the promise of the development and application of information technologies to render the city more transparent, legible and comprehensible. In New York, CUSP profiles itself as a world-leading research centre setting the agenda for urban informatics, pushing the boundaries of this emerging field. It promotes the developing of the capacity to generate and combine increasingly disparate sources of data in order to improve the efficiency of urban processes such as transport, energy use and waste management. In general, urban informatics employs 'large amounts of highly granular dynamic data' (Burke et al., 2010: 328-331), which:

include social networking sites, environmental systems and monitors, individual and institutional information sets of various kinds, RSS news feeds, and so on, and are understood as non-standard in urban terms. 
In exploring a variety of techniques available to describe a certain bridge, for example, Burke et al. (2010) describe the challenge of successfully integrating heterogeneous sources of data. Insisting on a dynamic and adaptable 'ecology of techniques', this requires extensive processes of data collection, parsing, conversing, formatting and filtering. Increased computational capabilities are put to work to facilitate these processes in order to visualise the complexities of urban systems in real-time (Townsend, 2009: xxv). Ultimately, as these developments are intimately linked with city planning and management, this should push theories about the functioning of the city to focus on increasingly short-term time frames, probing for a 'thinking of cities as being plannable in some sense over minutes, hours and days, rather than years, decades or generations' (Batty, 2013: 276). As such the PathoMap project fits directly into the CUSP's (2014: no pagination) objective of 'developing cost effective risk management and emergency management practices that address preparedness, mitigation, response and recovery for both natural and man-made disasters to assure safety and security'.

This notion of preparedness is analysed by Fearnley (2007), who traces the history of US public health policies as part of the national civil defence system characterised by a logic of preparedness in contrast to that of insurance. While the latter, as Fearnley shows, informed the post-war establishment of social welfare states with national health care systems in Europe, the logic of preparedness in the US focuses on the early detection of emergence of diseases and the mitigation of effects. In shifting attention from the surveillance of people to the surveillance of diseases under the regime of pathogen preparedness, Fearnley (2005: 2) locates the development of a system of 'syndromic surveillance'. This system aims to identify correlations between different data sources, such as: the records of emergency room patients' symptoms, the sales of pharmaceuticals, and registers of emergency calls. By continuously comparing data, the syndromic surveillance system hopes 'to detect an unexpected, improbable epidemic in its emergent stages' (Fearnley, 2005: 29). To be sure, the PathoMap is meant to function in conjunction with a host of other, more traditional, forms of monitoring of disease. For instance, Afshinnekoo et al. (2015) are able to assure the public that the findings of large amounts of antibiotic-resistant bacteria, as well as some instances of anthrax and bubonic plague, are no real threats by putting these into a wider context. Yet what is important is that the PathoMap adds to such a regime of preparedness, extending the velocity of detection by not only relying on the correlation of data associated with disease, but to directly shift 'attention on the microbial agents themselves' (Fearnley, 2007: 5). This marks a shift from derivative, 'imperfect and often anecdotal' (Koonin, 2013: no pagination) information to an ambition of direct, perfect and total knowledge which typifies urban informatics as a science. 
The rising importance of this concept of preparedness can be understood as part of a wider network of 'anticipatory action' arising from the increasing importance of new technologies in social and political life (Anderson, 2010). In the context of urban informatics, the formalisation and legitimation of anticipatory action as response to threats of terrorism, biosecurity and ecological disaster (Anderson, 2010) is routinely expressed in the field's selfproclaimed potential to deliver sustainable, efficient and resilient cities. These tendencies fundamentally reshape originally linear temporalities by bringing in particular ways - the future into the present; rewriting, in the process, the role of the past. The specificity of this consists largely of the way in which uncertainty is dealt with, as 'the proliferation of anticipatory action, and the emphasis on an open future, is inseparable from a spatial-temporal imaginary of life as contingency' (Anderson, 2010: 780). This imaginary entails, Anderson (2010: 781) argues, an emphasis on a complex world consisting of an infinite multiplicity of flows and rhythms, and on life as 'unpredictable, dynamic and non-linear'. Such a spatial-temporal imaginary can also be seen to motivate projects such as the PathoMap; asserting the complexity of the world and proposing money, sewer systems and subway stations as primary locations of data collection, with a focus on the always lurking danger of possibly lethal pathogens.

\section{A fluid topology}

Under urban informatics, the city - smart, sustainable, resilient - becomes a set of processes, monitored (preferably in real-time) through a wide range of (preferably automated) technologies (see also de Lange's chapter in this volume). These monitoring practices work together to establish a baseline to mark the data that counts as normal, against which the abnormal, exceptional and possibly disruptive can be recognised. This 'politics of possibility' (Amoore, 2013), does not count on a statistical extrapolation of a limited sample with clear temporal boundaries, but involves a continuous process of negotiation to demarcate normal from abnormal in order to enable a pre-emptive mode of intervention. If the monitoring of New York's microbiological life can be done increasingly automatically, this negotiation is what is at stake in the success of the PathoMap. As Chris Mason, project director, explains:

of course, [Mason] notes, just because they identified certain bacterial species in the subways, 'that doesn't mean they're pathogenic,' and a big concern is igniting fear in the public. At this point, it's unclear how predictive the microbial data will be, and 
'you don't want to have a panic attack,' he says. The first step, he adds, is simply to establish a baseline'. (Akst, 2013: no pagination)

Ideally, the highly granular detection methods of the PathoMap will be able to pick up emergence on the level of the individual microbe. However, the finding of 'strains of infectious bacteria such as Pseudomonas and Staphylococcus' in some of New York's subway stations (Akst, 2013: no pagination) becomes meaningful only if deemed to deviate from the norm. The PathoMap watches over the city's microbiome which is naturally in constant flux - viruses emerge and disappear. Metagenomic analysis of Penn Station, for instance, indicated strong variations of distinct types of microbes at different times of the day (Afshinnekoo et al., 2015). Yet only when these pass the threshold of the pathogenic - when it threatens the integrity of the city through a high-impact catastrophe - will it trigger the alarm to initiate necessary preventive measures to pre-empt the danger. In this sense, the timing of intervention becomes crucial: too late means that the city may be stricken by the disastrous effects of an infectious pandemic; too early, as Mason observes, and New York could be captured by an arguably even more infectious spell of panic.

As Afshinnekoo et al. (2015: 11) conclude in their evaluation, the achievement of a real-time monitoring system for the 'dynamics of the urban metagenome' will be to the benefit of large numbers of people. The vision of achieving an automated cycle of detection, evaluation and intervention enables the PathoMap to imagine the city as a fluid object. As a fluid object, constitutive elements and relations between elements may be added on or disposed of, but only 'gradually and incrementally' (Law and Mol, 2001: 614) if the coherence of the overall object is not to be disrupted. This is how continuous transformation establishes the invariance of the object in fluid space: 'so long as it flows there is the possibility that the transformations that it undergoes will not lead to abrupt changes' (Mol and Law, 1994: 658). In fluid space, the object is allowed to transform continuously, if only gradually and within a set of mobile and over-determinant boundaries. Here, change is inherent in the dynamics of the object - not subject to a linear past to be analysed through statistical methods focusing on discovering patterns to calculate probabilities. The relevance of the PathoMap hinges on the idea that New York City's microbiome is always in motion and it is precisely these dynamics which it aims to capture.

Mol and Law's notion of topology is deployed here to indicate how different spatial formations - i.e. heterologous topological spaces - carry with them concomitant conditions for the progression of time and the possibilities for change. In other words, fluid space is a conceptual framework that transcends a problematic opposition between space and time, 'to argue that they are integral 
to each other' (Massey, 2005: 47). The flow of time depends on the constant realignment of elements in space at the same time as the fluidity of space is conditional on the level of temporal openness. Massey's (2005: 48) charge that 'at a minimum, for time to be open, space must be in some sense open too' can thus be read backwards and forwards. This fluid imagination has a radical political potential, as it can offer a promise of a qualitatively different and hopefully better future. Whether or not the PathoMap fulfils such potential, however, depends on the nature of this fluidity. The crucial task for a critical object-oriented cartography is to assess to what extent it enables a topological imagination where the future is truly contingent and open to the unexpected. With the growing importance of all sorts of technological devices in society, it becomes essential to distinguish between those that gesture 'towards dynamics that are internal to socio-technical formations' and those that uphold more conventional and rigid conceptual separations between the social and the technological (Marres, 2012: 292, original emphasis).

\section{The pre-emption of possibility}

The topologically distinct fluid space is the spatial form of the time of 'becoming' and 'emerging' as inherent to Anderson's (2010) 'life as contingency' paradigm, which insists on the inherent uncertainty and unpredictability of the modern, global world. The PathoMap is prepared for the omnipresent, impending danger of the terrorist living amidst the daily flow of commuters, or for the possibility that lethal microbes are already living in New York's sewers, subways, parks, or even people's wallets - for 'in the eyes of authority - and maybe rightly so nothing looks more like a terrorist than the ordinary man' (Agamben, 2009: 23). In a world in which 'change cannot be understood as the linear outcome of past conditions or present trends', the prevention of pandemics works according to a logic where 'the causes of disaster are presumed to incubate within life' (Anderson, 2010: 782). Consequently, as the pre-emptive logic marks a shift from a politics of risk to a 'politics of the possible' (Amoore, 2013), 'disease surveillance as pathogen preparedness embodies a discontinuous or sporadic temporality of government' (Fearnley, 2007: 16). In this sporadic form of government, the PathoMap establishes a rhythm with the city from emergence to detection to intervention. In this way, it forms part of an urban assemblage in which both the map and the city figure as objects; such that the former is instrumental in the fluidity of the latter.

This fluidity is not the outcome of a pre-established assemblage, produced through the relationship between map and city, but is a result of the specific, 
non-relational capacity of the PathoMap to affect urban space. It is a direct result of the way the pre-emptive logic of anticipatory action that it enables, brings the future into the present. The focus on the omnipresent threat of pandemics marks the particular logic of anticipatory action enabled by the PathoMap project through its recourse to affect as 'component of passage between mechanisms, orders of phenomena, and modes of power' (Massumi, 2005: 7, original emphasis). In this passage, decisions are no longer based on logical argumentation and calculative reason but on an affective charging of the empirical object. This is the map as device in its 'para-empirical condition' (Kurgan, 2013: 35), standing alongside the empirical body of the metagenome. It produces an increasingly seamless connection between the separate facets of 'bioterrorism threat detection, rapid-response, and containment' (PathoMap, n.d.: no pagination) in two steps. First, it offers direct and complete knowledge of the urban microbiome encompassing it temporally (i.e. in real-time) and spatially. This allows the map to appear at its most transparent, as if it were in fact the territory. Second, it is able to translate this knowledge straight into a sign of alarm so that the fear of a bioterrorist attack or the outbreak of an epidemic manifests itself, without the need for the threat to materialise:

the identity of the possible object determines the affective quality of the actual situation. And that's a fact. Its quality has actualized, without the object itself materialising. It has taken affective passage from the future to the present, on the coattails of the timeinverse sign of alarm. (Massumi, 2005: 9, original emphasis)

Thus, the PathoMap becomes instrumental in turning - para-empirically - the detection of a particular form of microbiological life into a sign of alarm that transfers onto the actual, empirical object, the affective value of the virtual object of a bioterrorist attack. Parisi (2012), in her discussion of parametric design, puts this self-effecting mechanism of the affective decision in terms of a regime of topological control in order to think of anticipatory action as a specific way of structuring change and continuity. Through a system of 'generative programming of parameters', in which the real-time input of heterogeneous data sources are integrated and made to respond to each other, this form of design transforms the urban into 'one smooth machine of continual variation' (Parisi, 2012: 177). The 'discontinuous or sporadic temporality' observed by Fearnley corresponds to Massumi's (2005: 6-7) 'lightning brightness of the foregone conclusion'. The reason this conclusion becomes foregone is that it is based on the self-effecting mechanism of the affective fact, according to which the empirical fact as a sign of a possible future actualises the virtual affectively, without it needing to materialise in reality. Thus, a new politics of neoconservatism marks a 
'tension between continued growth and becoming in the open neoliberal field of the capitalist system, and the sovereign closure of the foregone event' (Massumi, 2005: 7). Most importantly with regard to time, the decision becomes based not on the 'indefinite future of the what-may-come', but instead on the certainty of the "'will have” of the always-will-have-been-already' (Massumi, 2005: 6).

Here a picture emerges not of possible futures emergent in the present - an open future, life as contingency - but rather of a predetermined course of action inscribing itself into the past in order to bypass the present, denying it any significant claim to agency. As the turn to real-time monitoring of possible threats displaces the focus on statistical methods to calculate the probable based on past trends, the past is not merely disposed of as a factor in the decision-making process. Instead, as the empirical detection of microbial emergence makes its affective passage into the sign of danger, the eventual decision to intervene comes 'in the mode of having always been already' (Massumi, 2005: 6). As 'the future-past colonises the present' (Massumi, 2005: 6), the latter is sidestepped with the disqualification of logical reason's ability to explain the decision in a linear argument - valuable only for the extraction of empirical facts. Thus, the pre-emptive logic not so much brings the future into the present, but rather imposes the former in order to suppress the latter which, as a moment of discussion, calculation and deliberation, has to be avoided for its disposition to the weakness of uncertainty. In this way, the PathoMap becomes a typically modern apparatus in Agamben's (2009) terms by way of its fundamentally desubjectifying effect. That is, it is enlisted by a form of governmentality in which urban planning is rendered purely in terms of technical questions - 'a pure activity of government that aims at nothing other than its own replication' (Agamben, 2009: 22). This form of governmentality goes hand in hand with a science of cities in which urban planning as a set of 'integrated, quantitative, predictive, science-based' (Bettencourt and West, 2010: 912) techniques is opposed to traditional evidence-based policy-making, prone to all sorts of disagreements, values and opinions (see also Gleeson, 2013).

\section{Conclusion}

To a degree, the project of the PathoMap certainly is imaginative: the creation and implementation of a pathogen weather map as a novel approach to syndromic surveillance testifies to a vivid imagination of the potential of new information technologies. Understood as a device (see for example Marres, 2012) it is able to mobilise a topological imagination, which establishes the city as a fluid object, not merely because of it being the object of a topological analysis, but 
because 'it is built into the technology itself' (De Laet and Mol, 2000: 225). The map then does not so much figure itself as a fluid object, a mutable mobile, but is instrumental in structuring reality in fluid terms. Accordingly, as a critical object-oriented cartography, it is important to evaluate the PathoMap by pointing towards the way in which the positing of the city as a fluid object by urban informatics enables a social imagination which opens up, or closes down, emergent possible futures. With respect to time, indicating a fluid topological imagination consolidated in the PathoMap fundamentally implies the assumption that 'the future will radically differ from the here and now' (Anderson, 2010: 780). Accordingly, in fluid space, object continuity is not so much maintained despite its transformation, but precisely because of it, 'for fluidity generates the possibility of invariant transformation' (Mol and Law, 1994: 658, original emphasis).

Yet, rather than appreciating the possibilities for continual, gradual change as a basis for invariant transformation, the PathoMap is devised to suppress uncertainty, keep novelty in check and guide it along the predetermined lines of the smart, resilient city, reassuring the public that the future will be fundamentally the same as the here and now. Rather than opening up the imagination to what the city could be, the PathoMap thus deploys a topological imagination of the fluid object in order to reinforce the grip on the possible according to established ideas about what the city should be. As such, it is part and parcel of a perspective which advocates the necessity of a 'grand unified theory of sustainability' in order to ultimately produce completely 'predictable cities' (Bettencourt and West, 2010: 912-913). Discussing the case of Songdo in South Korea, Halpern et al. (2013: 298-299) problematise precisely this politics of possibility as new epistemology of the emerging 'test-bed urbanism'. The real problem here is that 'when prediction collapses into production, we lose any possibilities of emergence, of change, or of dynamic life' (Halpern et al., 2013: 299). What the earlier critical cartographers, such as Harley, understood was that the representation in a map can never fully account for the territory - it will always, by definition, be an abstraction, with the inevitable loss of some of its qualities as a consequence. In other words, central to constructivist critical cartography was the critique of representation for its abstractive tendencies always taking away from the complexity of the territory.

The shift towards an object-oriented critical cartography, in contrast, hopes to open up the question of how maps can add to rather than subtract from this vibrancy and, thus, how they can 'help us feel more of the liveliness' (Bennett, 2012: 232) of the places they represent. An object-oriented critical cartography explores the particularity of a map not to isolate it from its environment, but to more adequately understand its relationship to other objects and its place in the 
system. It considers the agency of the map itself so that it is neither a product of larger regimes of power, nor a neutral representation of its territory.

To be sure, object-oriented or 'thing-materialist' analyses are relevant to the study of maps of all times. Yet arguably, the insistence on the affective capacity of the map as object becomes even more pertinent with the abundance of digital maps and data visualisations. Several elements of this are important: the ability to incorporate increasingly large datasets and draw together ever more disparate elements; the progressively near real-time capacity to respond to empirical fluctuations; and the proliferation of devices and the diverse forms of interaction they afford. All of these add to the complexity of relationships between the map and the territory and, moreover, highlight the influence of maps and their potential to affect. An object-oriented approach is meant to pay attention to these expanding affective capacities and, critically, to assess the extent to which maps in particular contexts actually advance and invigorate understandings of this complexity. Finally, in the context of temporality, this may imply thinking about how, rather than commanding the pre-emptive elimination of uncertainty, maps can prompt the speculative provocation of possibility.

\section{References}

Afshinnekoo, E., Meydan, C., Levy, S. and Mason, C. E. (2015) Geospatial resolution of human and bacterial diversity with city-scale metagenomics. CELS, 1(1): pp. 1-15.

Agamben, G. (2009) What Is an Apparatus and Other Essays. Translated by D. Kishik and S. Pedatella. Stanford, California: Stanford University Press.

Akst, J. (2013) Metropolome. The Scientist, December 1. [Online] Available at: www.thescientist.com/?articles.view/articleNo/38376/title/Metropolome/ (accessed 3 May 2015).

Amoore, L. (2013) The Politics of Possibility: Risk and Security Beyond Probability. Durham, North Carolina: Duke University Press.

Anderson, B. (2010) Preemption, precaution, preparedness: Anticipatory action and future geographies. Progress in Human Geography, 34(6): pp. 777-798.

Ash, J. (2013) Rethinking affective atmospheres: Technology, perturbation and space-times of the non-human. Geoforum, 49: pp. 20-28.

Batty, M. (2013) Big data, smart cities and city planning. Dialogues in Human Geography, 3(3): pp. 274-279.

Bennett, J. (2004) The force of things: Steps toward an ecology of matter. Political Theory, 32: pp. 347-372.

Bennett, J. (2012) Systems and things: A response to Graham Harman and Timothy Morton. New Literary History, 43(2): pp. 223-233. 
Bettencourt, L. and West, G. (2010) A unified theory of urban living. Nature, 467: pp. 912-913.

Bryant, L. (2013) Politics and speculative realism. Speculations: A Journal of Speculative Realism, 4: pp. 15-21.

Burke, A., Coorey, B., Hill, D. and Mcdermott, J. (2010) 'Urban micro-informatics: A test case for high-resolution urban modelling through aggregating public information sources'. In: Bharat, D., I. Kang Li, A. and Park, H. J. Hong Kong (eds) New Frontiers: Proceedings of the 15th International Conference on Computer-Aided Architectural Design Research in Asia, Hong Kong, pp. 327-336.

Campkin, B., Mogilevich, M. and Ross, R. (2014) How images shape our cities. The Guardian, December 1. [Online] Available at: www.theguardian.com/cities/2014/ dec/ 01 / picturing-place-how-images-shape-our-cities-snow-cholera-corbusier-graffiti (accessed 3 May 2015).

Crampton, J. W. (2001) Maps as social constructions: Power, communication and visualization. Progress in Human Geography, 25(2): pp. 235-252.

Crampton, J. W. and Krygier, J. (2006) An introduction to critical cartography. ACME: An International E-Journal for Critical Geographies, 4(1): pp. 11-33.

CUSP (Center for Urban Science and Progress) (2014) Research: Disciplines, Domains, and Projects. [Online] Available at: http://cusp.nyu.edu/research/ (accessed May 22 2014).

Dale, B. (2013) Mapping microbiotic life in New York City's guts. Next City, October 23. [Online] Available at: http://nextcity.org/daily/entry/mapping-microbiotic-life-innew-york-citys-guts (accessed 3 May 2015).

Darling, J. (2014) Another letter from the Home Office: Reading the material politics of asylum. Environment and Planning D: Society and Space, 32: pp. 484-500.

De Laet, M, and Mol, A. (2000) The Zimbabwe bush pump: Mechanics of a fluid technology. Social Studies of Science, 30(2): pp. 225-263.

Fearnley, L. (2005) From chaos to controlled disorder: Syndromic surveillance, bioweapons, and the pathological future. ARC Working Paper 1. [Online] Available at: http: / / anthropos-lab.net/wp/publications / 2007/01/fearn_chaos_to_disorder.pdf (accessed 22 May 2014).

Fearnley, L. (2007) Pathogens and the strategy of preparedness. ARC Working Paper 3. [Online] Available at: www.anthropos-lab.net/workingpapers/no3.pdf (accessed 22 May 2014).

Gleeson, B. (2013) What role for social science in the 'urban age'? International Journal of Urban and Regional Research, 37(5): pp. 1839-1851.

Halpern, O., LeCavalier, J., Calvillo, N. and Pietsch, W. (2013) Test-bed urbanism. Public Culture, 25(2): pp. 272-306.

Harley, J. B. (1989) Deconstructing the map. Cartographica, 26(2): pp. 1-20.

Harman, G. (2012) The well-wrought broken hammer: Object-oriented literary criticism. New Literary History, 43(2): pp. 183-203.

Hayles, N. K. (2014) Speculative aesthetics and object-oriented inquiry (OOI). Speculations: A Journal of Speculative Realism, 5: pp. 158-179. 
Hookway, B. (2014) Interface. Cambridge, Massachusetts: The Massachusetts Institute of Technology Press.

Kitchin, R. and Dodge, M. (2007) Rethinking maps. Progress in Human Geography, 31(3): pp. 331-344.

Kitchin, R., Gleeson, J. and Dodge, M. (2013) Unfolding mapping practices: A new epistemology for cartography. Transactions of the Institute of British Geographers, 38(3): pp. $480-496$.

Koonin, S. E. (2013) The promise of urban informatics. Center for Urban Science Progress, May 30. [Online] Available at: http://docplayer.net/5866972-Center-for-urbanscience-progress-the-promise-of-urban-informatics.html (accessed 1 August 2015).

Kurgan, L. (2013) Close Up at a Distance: Mapping, Technology and Politics. New York: Zone Books.

Law, J. and Mol, A. (2001) Situating technoscience: An inquiry into spatialities. Environment and Planning D: Society and Space, 19(5): pp. 609-621.

Law, J. and Ruppert, E. (2013) The social life of methods: Devices. Journal of Cultural Economy, 6(3): pp. 229-240.

Marres, N. (2012) On some uses and abuses of topology in the social analysis of technology (or the problem with smart meters). Theory, Culture and Society, 29(4/5): pp. 288-310.

Massey, D. (2005) For Space. London: Sage Publications.

Massumi, B. (2005) The future birth of an affective fact. Conference Proceedings: Genealogies of Biopolitics. [Online] Available at: http://browse.reticular.info/text/collected/massumi.pdf (accessed 1 May 2015).

Mol, A. and Law, J. (1994) Regions, networks and fluids: Anaemia and social topology. Social Studies of Science, 24(4): pp. 641-671.

New York University (2013) NYU announces winners of 'Grand Challenge' science competition. NYU News, September 23. [Online] Available at: www.nyu.edu/about/ news-publications/news/2013/09/23/nyu-announces-winners-of-grand-challengescience-competition.html (accessed 22 May 2014).

Parisi, L. (2012) Digital design and topological control. Theory, Culture and Society, 29(4/5): pp. 165-192.

PathoMap (n.d.) PathomapAbout. [Online] Available at: www.pathomap.org/about/ (accessed 22 May 2014).

Perkins, C. (2004) Cartography - cultures of mapping: Power in practice. Progress in Human Geography, 28(3): pp. 381-391.

Townsend, A. (2009) 'Foreword'. In: Foth, M. (eds) Handbook of Research on Urban Informatics: The Practice and Promise of the Real-Time City. Hershey, Pennsylvania: Information Science Reference, pp. xxiii-xxvii.

Wood, D. (1993) What makes a map a map? Cartographica, 30(2/3): pp. 81-86. 